\title{
Association between Expression of 8-0HdG and Cigarette Smoking in Non-small Cell Lung Cancer
}

\author{
Ae Ri An · Kyoung Min Kim \\ Ho Sung Park · Kyu Yun Jang \\ Woo Sung Moon · Myoung Jae Kang \\ Yong Chul Lee ${ }^{1} \cdot$ Jong Hun Kim ${ }^{2}$ \\ Han Jung Chae $\cdot$ Myoung Ja Chung
}

Departments of Pathology, ${ }^{1}$ Internal Medicine,

${ }^{2}$ Thoracic and Cardiovascular Surgery, and

${ }^{3}$ Pharmacology, Research Institute of Clinical

Medicine of Chonbuk National University,

Biomedical Research Institute of Chonbuk

National University Hospital, Research Institute

for Endocrine Sciences, Chonbuk National

University Medical School, Jeonju, Korea

Received: December 11, 2018

Revised: February 1, 2019

Accepted: February 20, 2019

\section{Corresponding Author}

Myoung Ja Chung, MD

Department of Pathology, Chonbuk National

University Medical School, 567 Baekje-daero,

Deokjin-gu, Jeonju 54896, Korea

Tel: $+82-63-270-3072$

Fax: +82-63-270-3135

E-mail: mjchung@jbnu.ac.kr
Background: Exposure to cigarette smoking (CS) is a major risk factor for the development of lung cancer. CS is known to cause oxidative DNA damage and mutation of tumor-related genes, and these factors are involved in carcinogenesis. 8-Hydroxydeoxyguanosine (8-OHdG) is considered to be a reliable biomarker for oxidative DNA damage. Increased levels of 8-OHdG are associated with a number of pathological conditions, including cancer. There are no reports on the expression of 8-OHdG by immunohistochemistry in non-small cell lung cancer (NSCLC). Methods: We investigated the expression of 8-OHdG and p53 in 203 NSCLC tissues using immunohistochemistry and correlated it with clinicopathological features including smoking. Results: The expression of $8-\mathrm{OHdG}$ was observed in $83.3 \%$ of NSCLC. It was significantly correlated with a low T category, negative lymph node status, never-smoker, and longer overall survival $(p<.05)$ by univariate analysis. But multivariate analysis revealed that $8-\mathrm{OHdG}$ was not an independent prognostic factor for overall survival in NSCLC patients. The aberrant expression of p53 significantly correlated with smoking, male, squamous cell carcinoma, and Ki-67 positivity $(p<.05)$. Conclusions: The expression of 8-OHdG was associated with good prognostic factors. It was positively correlated with never-smokers in NSCLC, suggesting that oxidative damage of DNA cannot be explained by smoking alone and may depend on complex control mechanisms.

Key Words: Carcinoma, non-small cell lung; 8-Oxo-7-hydrodeoxyguanosine; p53; Smoking; Immunohistochemistry
Lung cancer has been the most common cancer in the world for several decades and remains the leading cause of cancer deaths worldwide. ${ }^{1}$ Exposure to cigarette smoking (CS) is a major risk factor for the development of lung cancer. ${ }^{1}$ However, the exact mechanism by which CS is involved in lung cancer development is still unclear. Smoking is known as a major inducer of oxidative stress, which in turn is known to cause DNA damage and mutation of tumor-related genes, and these factors are involved in carcinogenesis.

Oxidative damage of DNA by reactive oxygen and nitrogen species leads to the production of 8-hydroxy-2-deoxy guanosine (8-OHdG), which is a specific biomarker of oxidative stress. Increased levels of 8-OHdG are associated with the aging process as well as a number of pathological conditions, including cancer, diabetes, and hypertension. ${ }^{2}$ Previous studies reported that increased 8-OHdG expression in cancer was associated with a poor prognosis. ${ }^{3}$ However, the clinical significance of $8-\mathrm{OHdG}$ expression as a biomarker is still controversial. Negative $8-\mathrm{OHdG}$ expression was associated with an aggressive cancer phenotype. ${ }^{4}$ Also, 8-OHdG has been measured in urine or serum rather than in cancer tissue, and there is no report of the expression of $8-\mathrm{OHdG}$ by immunohistochemistry of non-small cell lung cancer (NSCLC). Therefore, we thought that it would be meaningful to measure $8-\mathrm{OHdG}$ in cancer tissues by immunohistochemistry and to examine the relationship between their expression and clinicopathologic factors.

p53 is an important transcription factor regulating intracellular pathways related to cell survival, DNA-repair, and apoptosis. TP53 mutations are one of the most common mutations found in lung cancers and occur more frequently in smoking- 
related lung cancer. It is known that the common types of cancerassociated TP53 mutations not only lose tumor suppression function but acquire a function related to tumor progression, such as cell-cycle progression or cell migration. This leads to malignant transformation and cancer progression. Oxidative stress is known to play an important role in $\mathrm{p} 53$ mutations caused by smoking. ${ }^{5}$ It is known that impaired capability of mutant $\mathrm{p} 53$ to promote DNA repair leads to cancer development. Previous studies showed that positive immunoreactivity for $8-\mathrm{OHdG}$ was more frequent in cases positive for $\mathrm{p} 53$ in malignant melanoma. ${ }^{6}$

To better understand the role of oxidative damage in carcinogenesis in lung cancer, we examined the expression of 8-OHdG in non-small cell lung cancer using immunohistochemistry and correlated with clinicopathologic features including smoking and p53 expression.

\section{MATERIALS AND METHODS}

\section{Patients and follow-up}

This study evaluated NSCLC patients who underwent surgical resection between January 2007 and December 2012. Among them, 203 NSCLC had complete available medical records, original hematoxylin and eosin slides, and paraffin-embedded tissue blocks. Clinical information including smoking history and postoperative follow-up was obtained by reviewing the medical records. The pathologic diagnosis and staging were reviewed according to the 8th American Joint Committee on Cancer staging system and World Health Organization classification. The classification of smoking status follows the Centers for Disease Control and Prevention guidelines, and the status categories were "Never," "Former" (adults who have smoked at least 100 cigarettes in their lifetime, but say they currently do not smoke), or "Current" (adults who have smoked 100 cigarettes in their lifetime and currently smoke cigarettes). This study was approved by the institutional review board of Chonbuk National University Hospital (CUH 2017-09-029-001). All samples derived from the National Biobank of Korea were obtained with informed consent under institutional review board-approved protocols.

\section{Immunohistochemical staining and scoring}

Formalin-fixed paraffin-embedded tissue of NSCLC patients were used to establish tissue microarrays. Original hematoxylin and eosin slides were reviewed, and one 3.0-mm-sized core from the representative area was taken. The tissue sections were de- paraffinized and boiled in an antigen retrieval solution (citrate, $\mathrm{pH}$ 6.0) for 20 minutes in a cooker. The primary antibodies for 8-OHdG (1:200, N45.1, JaiCA, Shizuoka, Japan), p53 (1:800, DO-7, Leica, London, UK), and Ki-67 (1:100, MIB-1, Dako, Glustrup, Denmark) were used for immunohistochemical staining. The slides that had been stained for 8-OHdG, p53, and Ki-67 were evaluated by two pathologists (M.J.C. and A.R.A.) who had no clinicopathologic information on the patients. Immunohistochemical staining was evaluated to estimate the nuclear positivity of tumor cells for each marker, and the stained area was semiquantitatively recorded for the area of positive cells in $5 \%$ increments.

Immunohistochemical staining for $8-\mathrm{OHdG}$ and $\mathrm{Ki}-67$ was considered positive when $\geq 5 \%$ and $\geq 10 \%$ of the tumor cells showed moderate to strong nuclear staining, respectively. The cut-off points for the immunohistochemical staining score were determined by receiver operating characteristic (ROC) curve analysis. It has recently been reported that immunohistochemical staining for $\mathrm{p} 53$ can be used as a surrogate for TP53 mutation analysis. ${ }^{89}$ Complete negative and high expression showed strong correlation with TP53 mutation. ${ }^{8,9}$ We categorized immunohistochemical results for $\mathrm{p} 53$ into three groups as negative, low (1\%-50\% positively stained nuclei), and high (> 50\% positively stained nuclei) as previously reported. ${ }^{10}$ Then, $\mathrm{p} 53$ immunohistochemical staining was defined as "aberrant expression" in the p53 negative and high expression group and "wild type expression" in the p53 low expression group. ${ }^{10}$

\section{Statistical analysis}

ROC curve analysis was used to determine the cut-off points for immunohistochemical staining. The cutoff points for 8-OHdGand $\mathrm{Ki}-67$-positivity were determined at the point with the highest area under the curve (AUC) to estimate survival of NSCLC patients. Because the ROC curve is a plot of the true positive rate (sensitivity) versus the false positive rate (1-specificity) for determination of patient death, the cutoff level for the ideal test is presented as sensitivity 1 and specificity 1 (AUC, 1.000). Therefore, we chose the cut-off point at the highest AUC value.

The date of last follow-up was recorded as the last contact or the death of patients through August 2017. The prognosis of NSCLC patients was evaluated by analyzing overall survival (OS). The death of the patient from lung cancer was considered an event for OS analysis. SPSS software ver. 22.0 (IBM Corp., Armonk, NY, USA) was used to perform statistical analysis for the univariate and multivariate Cox proportional hazards regression analyses, Kaplan-Meier survival analysis, and Pearson's chi-square test. The 
p-values less than 0.05 were considered statistically significant.

\section{RESULTS}

\section{Correlations between 8-OHdG expression and clinicopatho- logic parameters of NSCLC patients}

In this study, the NSCLC used consisted of 94 squamous cell carcinomas and 109 adenocarcinomas. The mean age of the study subjects was 65 years. In all, $72.4 \%$ of the subjects were male, and $27.3 \%$ were female. Expression of 8-OHdG was found exclusively in nuclei of tumor cells and was positive in $83.3 \%$ (169/203) of NSCLC samples (Table 1, Fig. 1). The positive expression of $8-\mathrm{OHdG}$ was significantly associated with female, adenocarcinoma, smaller tumor size, lower $\mathrm{T}$ group, negative lymph node status, and never-smoker $(\mathrm{p}<.05)$ (Table 1). The expression of 8 -OHdG was high in never-smoker (89.5\%) compared to smoker $(73.4 \%)(\mathrm{p}=.003)$.

For p53 immunohistochemistry, 18\% (37/203), 30\% (60/203),

Table 1. Clinicopathologic characteristics and the expression of 8-OHdG in non-small cell lung carcinomas

\begin{tabular}{|c|c|c|c|c|}
\hline Characteristic & No. & $8-\mathrm{OHdG}(+)$ & 8-OHdG (-) & $p$-value \\
\hline \multicolumn{5}{|l|}{ Age (yr) } \\
\hline$<65$ & 84 & 71 (84.5) & $13(15.5)$ & \multirow[t]{2}{*}{.683} \\
\hline$\geq 65$ & 119 & 98 (82.4) & 21 (17.6) & \\
\hline \multicolumn{5}{|l|}{ Sex } \\
\hline Male & 144 & 115 (79.9) & $29(20.1)$ & \multirow[t]{2}{*}{.030} \\
\hline Female & 59 & $54(91.5)$ & 5 (8.5) & \\
\hline \multicolumn{5}{|l|}{ Histologic type } \\
\hline SqCC & 94 & $73(77.7)$ & 21 (22.3) & \multirow[t]{2}{*}{.037} \\
\hline $\mathrm{ADC}$ & 109 & 96 (89.1) & $13(10.9)$ & \\
\hline \multicolumn{5}{|l|}{ T category } \\
\hline $1+2$ & 119 & 109 (91.6) & $10(8.4)$ & \multirow[t]{2}{*}{$<.001$} \\
\hline $3+4$ & 84 & 60 (71.4) & $24(28.6)$ & \\
\hline \multicolumn{5}{|l|}{$\mathrm{N}$ category } \\
\hline NO & 108 & 100 (92.6) & $8(7.4)$ & \multirow[t]{2}{*}{$<.001$} \\
\hline $\mathrm{N} 1$ & 95 & 69 (72.6) & $26(27.4)$ & \\
\hline \multicolumn{5}{|l|}{ Pleural invasion } \\
\hline Negative & 135 & $117(86.7)$ & 18 (13.3) & \multirow[t]{2}{*}{.066} \\
\hline Positive & 68 & $52(76.5)$ & $16(23.5)$ & \\
\hline \multicolumn{5}{|l|}{ Smoking } \\
\hline Never & 124 & $111(89.5)$ & $13(10.5)$ & \multirow[t]{2}{*}{.003} \\
\hline Former + current & 79 & $58(73.4)$ & 21 (26.6) & \\
\hline \multicolumn{5}{|l|}{ p53 } \\
\hline Wild-type & 60 & $54(90.0)$ & $6(10.0)$ & \multirow[t]{2}{*}{.095} \\
\hline Aberrant & 143 & $115(80.4)$ & 28 (19.6) & \\
\hline \multicolumn{5}{|l|}{ Ki-67 } \\
\hline Negative & 47 & $43(91.5)$ & $4(8.5)$ & \multirow[t]{2}{*}{.084} \\
\hline Positive & 156 & $126(80.8)$ & 30 (19.2) & \\
\hline
\end{tabular}

Values are presented as number (\%).

8-OhdG, 8-hydroxy-2-deoxy guanosine; SqCC, squamous cell carcinoma; $A D C$, adenocarcinoma. and $52 \%(106 / 203)$ of cases were categorized as p53 negative, p 53 low, and p53 high groups, respectively. Analysis was performed on the correlations between $\mathrm{p} 53$ staining pattern and clinicopathological features of NSCLC patients, and $\mathrm{p} 53$ aberrant expression was significantly correlated with male, smoker, squamous cell carcinoma, and Ki-67 positivity ( $<<.05)$ (Table 2). The p53 wild-type expression was high in never-smoker (39.5\%) compared to smoker (13.9\%), and p53 aberrant expression was $86.1 \%$ (68/79) in smoker and 60.5\% (75/124) in never-smoker $(\mathrm{p}<.001)$. The $\mathrm{p} 53$ aberrant expression rate was $87.2 \%$ in squamous cell carcinoma and $56 \%$ in lung adenocarcinoma. In the 8-OHdG negative group, $\mathrm{p} 53$ aberrant expression pattern was more frequent $(82.4 \%, 28 / 34)$ than in the $8-\mathrm{OHdG}$ positive group $(68 \%, 115 / 169)$ but not to an extent that was statistically significant $(\mathrm{p}=.095)$. Comparing the $\mathrm{p} 53$ wild-type and the $\mathrm{p} 53$ aberrant patients, there was no significant difference in tumor stage or lymph node stage.

\section{NSCLC patients with negative 8-OHdG expression had shorter $\mathrm{OS}$ by univariate analysis}

When univariate Cox proportional regression analysis was performed for the survival of NSCLC patients, older age $(\geq 65)$, male, smoker, higher tumor stage, presence of lymph node metastasis, 8-OHdG negativity and p53 aberrant expression, and Ki-67 positivity showed significant association with shorter OS of NSCLC patients by univariate analysis (Table 3). The patients with 8-OHdG negativity showed 1.847 -fold (95\% confidence interval [95\% CI], 1.054 to 3.236; $\mathrm{p}=.032$ ) greater risk of death. Smoking (former and current) predicted a 3.926-fold (95\% CI, 2.302 to $6.697 ; \mathrm{p}<.001)$ greater risk of death than the neversmoker group. The $\mathrm{p} 53$ aberrant expression group predicted a 2.031-fold (95\% CI, 1.057 to 3.900; $\mathrm{p}=.033$ ) greater risk of death than the p53 wild-type group. Kaplan-Meier survival analysis was used to analyze the prognostic impact of the expression of 8-OHdG, p53, and Ki-67 and smoking and tumor stage on OS, and the results are presented in Fig. 2.

The multivariate analysis included the factors that showed pvalue lower than .05 in univariate analysis (sex, age, smoking, $\mathrm{T}$ category, lymph node stage, p53 expression, Ki-67 expression, and 8-OHdG expression). Age older than 65, smoker, and higher $\mathrm{T}$ category in the TNM stage system were independent poor prognostic factors for OS of NSCLC patients (Table 4). However, multivariate analysis did not indicate that $8-\mathrm{OHdG}$ expression was an independent prognostic factor associated with OS for NSCLC. 

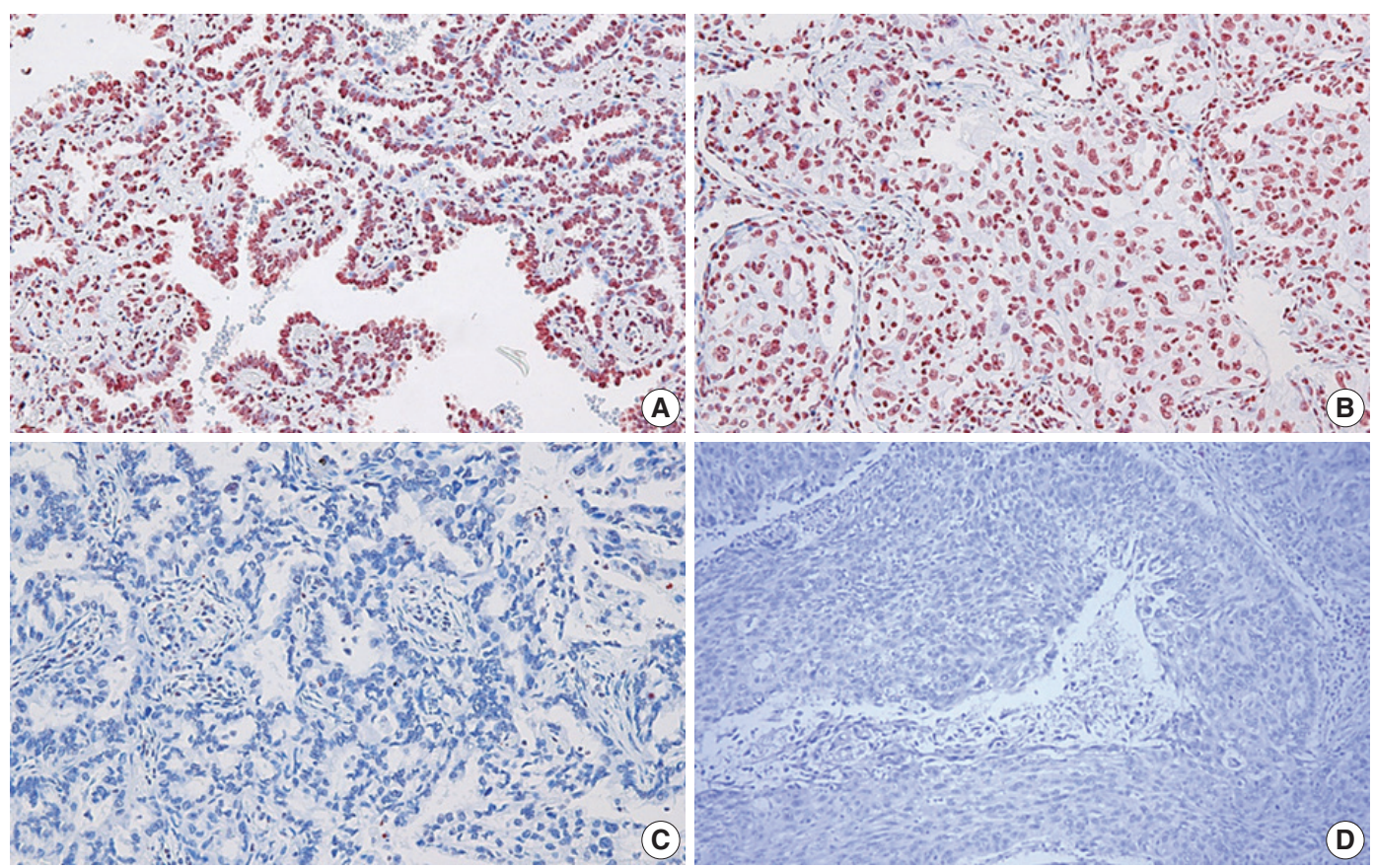

Fig. 1. Immunohistochemical expression of 8-hydroxydeoxyguanosine (8-OHdG) in non-small cell carcinomas. Expression of 8-OHdG in nuclei of tumor cells. (A, B) Adenocarcinoma. (C, D) Squamous cell carcinoma.

\section{DISCUSSION}

In this study, we investigated the immunohistochemical expression of 8-OHdG and p53 in human NSCLC tissues. Our results show that (1) expression of $8-\mathrm{OHdG}$ was observed in 83.3\% of NSCLC tissue; (2) expression of 8-OHdG was significantly associated with low $\mathrm{T}$ category, negative lymph node status, and never-smoker; (3) expression of 8-OHdG was significantly associated with longer OS by univariate and Kaplan-Meier survival analysis; (4) p53 aberrant expression closely correlated with smoker, male, squamous cell carcinoma, and Ki-67 positivity.

CS induces oxidative stress, which can cause severe DNA damage and is known as an important carcinogenic mechanism linked to NSCLC. It is challenging to perform a direct measurement of reactive oxygen species (ROS) because of their short lifetime and rapid degradation and removal by cellular defense mechanisms. Therefore, a useful method to assess ROS is to use antibodies against the specific "footprints" of oxidative damage. The oxidative damage of DNA by ROS produces $8-\mathrm{OHdG}$, and this serves as an established footprint of oxidative stress. Increased levels of 8-OHdG are associated with the aging process as well as with a number of pathological conditions including cancer, diabetes, and hypertension. ${ }^{2}$

The overexpression of 8-OHdG has been reported in a variety of cancers, including breast cancer, lung cancer, bladder cancer, colorectal cancer, renal cell carcinoma, prostate cancer, and gastric adenocarcinoma. ${ }^{4,11-15}$ Reports have predominantly indicated that overexpression of $8-\mathrm{OHdG}$ is associated with unfavorable prognostic factors and/or poor patient prognosis. However, some studies reported different results. Negative 8-OHdG expression was associated with an aggressive breast cancer phenotype, and some reports have found no difference in 8-OHdG level between cancer patients and healthy subjects. ${ }^{4,16-18}$ Therefore, there is controversy surrounding the clinical significance of $8-\mathrm{OHdG}$ expression. Our results showed that tumors with positive expression of 8-OHdG were significantly associated with favorable clinicopathologic factors and longer OS in NSCLC patients. We considered the following possibilities as the cause of the different results. In many of the previous studies, $8-\mathrm{OHdG}$ was measured in urine or at the serum level, not in cancer tissue. It is known that the method of measuring the absolute amount of 8-OHdG in urine or serum can be influenced by artificial production of $8-\mathrm{OHdG}$ in the sample preparation stage. ${ }^{19,20}$ Also, a previous study showed that serum and urinary levels of $8-\mathrm{OHdG}$ did not associate with those found in the tissues. ${ }^{21}$ We detected 8-OHdG expression using immunohistochemistry because immunohistochemical procedures allow detection of 8-OHdG at the single-cell level, which has the advantage of directly confirming its expression in cancer cells in tissues composed of different cell populations. ${ }^{22}$ To the best of our knowledge, this is the first study to use 
Table 2. Clinicopathologic characteristics and the expression of p53 in non-small cell lung carcinomas

\begin{tabular}{|c|c|c|c|c|}
\hline \multirow{2}{*}{ Characteristic } & \multicolumn{3}{|c|}{ p53 } & \multirow{2}{*}{$p$-value } \\
\hline & No. & Wild-type & Aberrant & \\
\hline \multicolumn{5}{|l|}{ Age (yr) } \\
\hline$<65$ & 84 & 24 (28.6) & $60(71.4)$ & .796 \\
\hline$\geq 65$ & 119 & $36(30.3)$ & $19(16.0)$ & \\
\hline \multicolumn{5}{|l|}{ Sex } \\
\hline Male & 144 & $32(22.2)$ & $112(77.8)$ & $<.001$ \\
\hline Female & 59 & $28(47.5)$ & 8 (13.6) & \\
\hline \multicolumn{5}{|l|}{ Histologic type } \\
\hline SqCC & 94 & $12(12.8)$ & 82 (87.2) & $<.001$ \\
\hline ADC & 109 & 48 (44.0) & $61(56.0)$ & \\
\hline \multicolumn{5}{|l|}{ T category 8th } \\
\hline $1+2$ & 119 & 40 (33.6) & 79 (66.4) & .132 \\
\hline $3+4$ & 84 & $20(23.8)$ & 64 (76.2) & \\
\hline \multicolumn{5}{|l|}{$\mathrm{N}$ category } \\
\hline NO & 108 & 36 (33.3) & $72(66.7)$ & .301 \\
\hline $\mathrm{N} 1$ & 95 & $24(25.3)$ & $71(74.4)$ & \\
\hline \multicolumn{5}{|l|}{ Pleural invasion } \\
\hline Negative & 135 & $41(30.4)$ & $94(69.6)$ & .720 \\
\hline Positive & 68 & $19(27.9)$ & 49 (72.1) & \\
\hline \multicolumn{5}{|l|}{ Smoking } \\
\hline Never & 124 & 49 (39.5) & 75 (60.5) & $<.001$ \\
\hline Former + current & 79 & $11(13.9)$ & 68 (86.1) & \\
\hline \multicolumn{5}{|l|}{ 8-OHdG } \\
\hline Negative & 34 & $6(17.6)$ & 28 (82.4) & .095 \\
\hline Positive & 169 & 54 (32.0) & $115(68.0)$ & \\
\hline \multicolumn{5}{|l|}{ Ki-67 } \\
\hline Negative & 47 & $22(46.8)$ & 25 (53.2) & .003 \\
\hline Positive & 156 & $38(24.4)$ & $118(75.6)$ & \\
\hline
\end{tabular}

Values are presented as number (\%).

SqCC, squamous cell carcinoma; ADC, adenocarcinoma; 8-OHdG, 8-hydroxy-2-deoxy guanosine.

immunohistochemistry to investigate the correlation between 8-OHdG expression and prognosis in NSCLC patients.

Several possible mechanisms may be behind the inverse association of 8-OHdG level and tumor aggressiveness. Sova et al. ${ }^{4}$ have insisted that the increase in ROS induces the overproduction of antioxidant enzymes, thereby avoiding the death of tumor cells and inducing tumor growth. Overproduction of antioxidant enzymes would prevent ROS interaction with DNA, leading to decreased formation of 8-OHdG at the tissue level, as suggested by their results. ${ }^{4}$ Another reasonable possibility we suggest is that cancer tissue is generally hypoxic, which is predicted to be the reason for low ROS in cancer cells, because oxygen is needed for production of ROS. Thus, ROS production is low in rapidly growing cancers, leading to a decrease in the production of 8-OHdG, which may explain the poor prognosis of negative $8-\mathrm{OHdG}$ in NSCLC patients in this study. Although there was no statistical significance, the association between pos-
Table 3. Univariate Cox regression analysis for the survival of NSCLC patients

\begin{tabular}{lcr}
\hline \multirow{2}{*}{ Characteristic } & \multicolumn{2}{c}{ OS (n=203) } \\
\cline { 2 - 3 } & \multicolumn{1}{c}{$\mathrm{HR}(95 \% \mathrm{Cl})$} & $\mathrm{p}$-value \\
\hline Age, $\geq 65$ yr (vs <65 yr) & $2.153(1.231-3.764)$ & .007 \\
Sex, female (vs male) & $0.324(0.154-0.681)$ & .003 \\
T category, T3+4 (vs 1+2) & $4.027(2.318-6.993)$ & $<.001$ \\
N category, N1 (vs N0) & $3.620(2.042-6.418)$ & $<.001$ \\
Pleural invasion, positive (vs negative) & $1.403(0.844-2.331)$ & .191 \\
Smoking, former + current (vs never) & $3.926(2.302-6.697)$ & $<.001$ \\
8-OHdG negative (vs positive) & $1.847(1.054-3.236)$ & .032 \\
p53 aberrant (vs wild-type) & $2.031(1.057-3.900)$ & .033 \\
Ki-67 positive (vs negative) & $4.982(1.808-13.731)$ & .002 \\
\hline
\end{tabular}

NSCLC, non-small cell lung cancer; 8-OHdG, 8-hydroxy-2-deoxy guanosine.

itive 8-OHdG and negative Ki-67 ( $\mathrm{p}=.084)$ in this study may support this hypothesis. Previous studies showed that ROSmediated DNA damage plays a role in the initiation of carcinogenesis as well as in malignant transformation. ${ }^{17,23}$ The expression of 8-OHdG decreased significantly in invasive breast carcinomas compared to non-invasive lesions, namely usual ductal hyperplasia, atypical ductal hyperplasia, and ductal carcinoma in situ. ${ }^{17}$ To support the hypothesis that ROS-mediated DNA damage may be involved in the early stages of cancer development rather than cancer progression, examination of $8-\mathrm{OHdG}$ expression in pre-cancerous lesions or pre-invasive lung cancer lesions is necessary. In addition, a DNA repair enzyme assessment is needed to clarify the fundamental background behind the current results.

In this study, expression of 8-OHdG was significantly associated with never-smoker $(\mathrm{p}=.003)$. We cannot explain the exact mechanism for the relationship between never-smokers and 8OHdG expression in this study. However, we inferred some possibilities based on the results of other researchers. The formation of carboxyhemoglobin in smokers can lower the ability of hemoglobin to deliver $\mathrm{O}_{2}$ (toxic hypoxia) and result in hypoxia. In turn, this can reduce ROS formation and lower the expression of 8$\mathrm{OHdG}^{24,25}$ The association between smoking and low 8-OHdG may also be explained by smoking-induced oxidative stress, i.e., overproduction of antioxidant enzymes. The state of the smoking-ROS-8-OHdG axis in the mechanism of NSCLC development by smoking is thought to be regulated by more complex regulatory mechanisms, including the functional status of ROS and antioxidant enzymes and the hypoxic environment of cancer.

DNA adduct formation and oncogenic mutation in lung epithelial cells are caused by chronic exposure to carcinogens in CS, and the accumulation of mutations is known to be involved in lung cancer development. TP53 mutation is an important muta- 

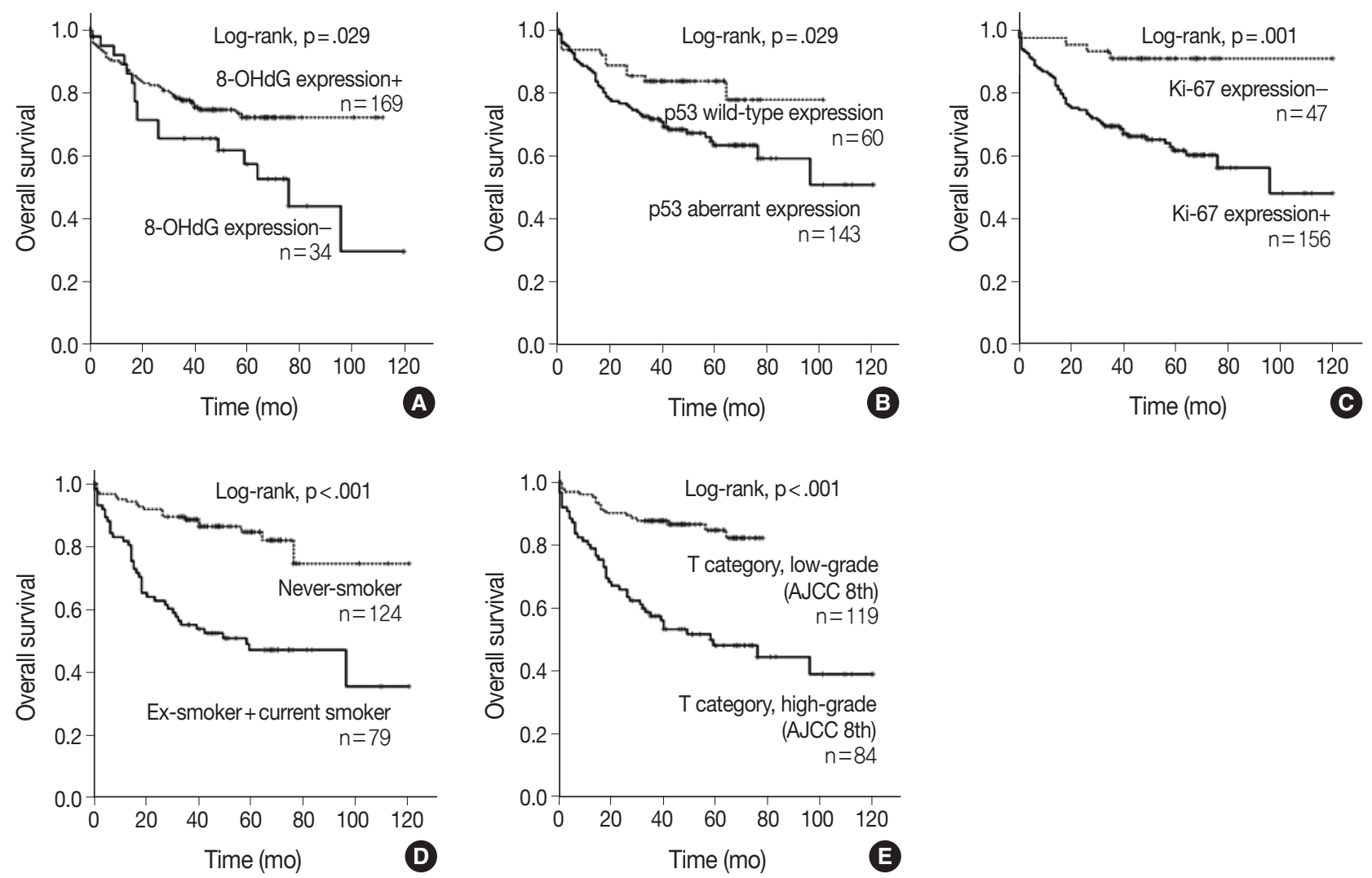

Fig. 2. Kaplan-Meier survival analysis of non-small cell lung carcinoma patients. Overall survival in 203 patients according to the expression of 8-hydroxydeoxyguanosine (8-OHdG) (A), p53 (B), Ki-67 (C), smoking history (D), and T category (American Joint Committee on Cancer (AJCC) 8th edition) (E).

Table 4. Multivariate Cox regression analysis for the survival of NSCLC patients

\begin{tabular}{lcc}
\hline \multirow{2}{*}{} & \multicolumn{2}{c}{ Total $(\mathrm{n}=203)$} \\
\cline { 2 - 3 } & $\mathrm{HR}(95 \% \mathrm{Cl})$ & $\mathrm{p}$-value \\
\hline T category, T 3,4 (vs 1,2) & $2.346(1.267-4.343)$ & .007 \\
Smoking, former + current (vs never) & $2.371(1.347-4.172)$ & .003 \\
Age, $\geq$ 65 yr (vs < 65 yr) & $2.154(1.220-3.804)$ & .008 \\
8-OHdG negative (vs positive) & $1.486(0.520-4.246)$ & .460 \\
p53 aberrant (vs wild-type) & $1.211(0.671-2.184)$ & .525 \\
\hline
\end{tabular}

Variables considered in the model were age, lymph node status, smoking history, T category (American Joint Committee on Cancer 8th edition), 8-OHdG expression and p53, Ki-67 expression.

NSCLC, non-small cell lung cancer; 8-OHdG, 8-hydroxy-2-deoxy guanosine.

tion associated with CS exposure, and loss of wild-type p53 function and increased mutant p53 function due to TP53 mutation are important in NSCLC carcinogenesis. It has recently been reported that immunohistochemical staining for $\mathrm{p} 53$ can be used as a surrogate for TP53 mutation analysis. ${ }^{8}$ In this study, p53 immunohistochemical staining was classified as wild or aberrant expression, and the correlation between p53 staining pattern and clinicopathologic features of NSCLC patients was analyzed.
The p53 aberrant expression rate was $87.2 \%$ in squamous cell carcinoma and $56 \%$ in lung adenocarcinoma (data not shown). Our results are consistent with another report that found $\mathrm{p} 53$ mutations in $46 \%$ of lung adenocarcinomas and $81 \%$ of squamous cell carcinomas. ${ }^{5}$ The p53 aberrant expression is closely correlated with smoker $(\mathrm{p}=.000)$, male $(\mathrm{p}=.000)$, squamous cell carcinoma $(\mathrm{p}=.000)$, and Ki-67 positivity $(\mathrm{p}=.003)$. Further studies are needed to determine the concordance of p53 immunohistochemistry with TP53 mutations in NSCLC to confirm our assertion.

In conclusion, this study has demonstrated the expression of 8-OHdG and p53 in NSCLC and its relationship with clinicopathologic factors and patient survival. Univariate analysis revealed that expression of $8-\mathrm{OHdG}$ was significantly associated with longer OS. Smoking is an important inducer of oxidative stress, but it was not associated with increased expression of 8-OHdG in this study, suggesting that more complex regulatory mechanisms regulate $8-\mathrm{OHdG}$ expression in cancer, including the functional status of the antioxidant enzyme and the hypoxic environment of cancer. The aberrant expression patterns of $\mathrm{p} 53$ 
immunohistochemical staining showed significant associations with smoking status.

\section{ORCID}

Ae Ri An: https://orcid.org/0000-0002-6047-1627

Kyoung Min Kim: https://orcid.org/0000-0001-7074-7183

Ho Sung Park: https://orcid.org/0000-0002-4879-874X

Kyu Yun Jang: https://orcid.org/0000-0002-5276-4446

Woo Sung Moon: https://orcid.org/0000-0001-7951-9865

Myoung Jae Kang: https://orcid.org/0000-0003-3662-0693

Yong Chul Lee: https://orcid.org/0000-0002-0433-509X

Jong Hun Kim: https://orcid.org/0000-0001-9289-1178

Han Jung Chae: https://orcid.org/0000-0003-4190-9889

Myoung Ja Chung: https://orcid.org/0000-0003-4165-7167

\section{Author Contributions}

Conceptualization; ARA, KMK, HSP, KYJ, WSM, MJK, YCL, JHK, HJC, MJC.

Data curation: ARA, KMK, HSP, MJC.

Formal analysis: ARA, KMK, HJC, MJC.

Funding acquisition: MJC.

Methodology: ARA, HJC, MJC, YCL.

Writing—original draft: ARA, KMK, HSP, KYJ, WSM,

MJK, YCL, JHK, MJC.

Writing—review \& editing: ARA, KMK, MJC.

\section{Conflicts of Interest}

The authors declare that they have no potential conflicts of interest.

\section{Acknowledgments}

The biospecimens for this study were provided by the Chonbuk National University Hospital Biobank, a member of the Korea Biobank Network, which is supported by the Ministry of Health, Welfare, and Family Affairs, Republic of Korea.

\section{REFERENCES}

1. Ferlay J, Soerjomataram I, Ervik M, et al. Cancer incidence and mortality worldwide: IARC CancerBase No. 11. Lyon: International Agency for Research on Cancer, 2014.

2. David SS, O'Shea VL, Kundu S. Base-excision repair of oxidative DNA damage. Nature 2007; 447: 941-50.

3. Matsumoto K, Satoh Y, Sugo H, et al. Immunohistochemical study of the relationship between 8-hydroxy-2'-deoxyguanosine levels in noncancerous region and postoperative recurrence of hepatocellu- lar carcinoma in remnant liver. Hepatol Res 2003; 25: 435-41.

4. Sova H, Jukkola-Vuorinen A, Puistola U, Kauppila S, Karihtala P. 8-Hydroxydeoxyguanosine: a new potential independent prognostic factor in breast cancer. Br J Cancer 2010; 102: 1018-23.

5. Gibbons DL, Byers LA, Kurie JM. Smoking, p53 mutation, and lung cancer. Mol Cancer Res 2014; 12: 3-13.

6. Murtas D, Piras F, Minerba L, et al. Nuclear 8-hydroxy-2'-deoxyguanosine as survival biomarker in patients with cutaneous melanoma. Oncol Rep 2010; 23: 329-35.

7. Rami-Porta R, Asamura H, Travis WD, Rusch VW. Lung. In: Amin $\mathrm{MB}$, ed. AJCC cancer staging manual. 8th ed. Cham: Springer, 2017; 431-56.

8. Yemelyanova A, Vang R, Kshirsagar M, et al. Immunohistochemical staining patterns of p53 can serve as a surrogate marker for TP53 mutations in ovarian carcinoma: an immunohistochemical and nucleotide sequencing analysis. Mod Pathol 2011; 24: 1248-53.

9. Cha YJ, Kim HR, Lee CY, Cho BC, Shim HS. Clinicopathological and prognostic significance of programmed cell death ligand-1 expression in lung adenocarcinoma and its relationship with p53 status. Lung Cancer 2016; 97: 73-80.

10. Shim HS, Kenudson M, Zheng Z, et al. Unique genetic and survival characteristics of invasive mucinous adenocarcinoma of the lung. J Thorac Oncol 2015; 10: 1156-62.

11. Shen J, Deininger P, Hunt JD, Zhao H. 8-Hydroxy-2'-deoxyguanosine $(8-\mathrm{OH}-\mathrm{dG})$ as a potential survival biomarker in patients with nonsmall-cell lung cancer. Cancer 2007; 109: 574-80.

12. Kaczmarek P, Blaszczyk J, Fijalkowski P, et al. Assessment of 8-hydroxy-2'-deoxyguanosine concentrations in bladder cancer patients treated with intravesical BCG instillation. Pol Merkur Lekarski 2005; 19: 526-8.

13. Oliva MR, Ripoll F, Muniz P, et al. Genetic alterations and oxidative metabolism in sporadic colorectal tumors from a Spanish community. Mol Carcinog 1997; 18: 232-43.

14. Okamoto K, Toyokuni S, Uchida K, et al. Formation of 8-hydroxy-2'deoxyguanosine and 4-hydroxy-2-nonenal-modified proteins in human renal-cell carcinoma. Int J Cancer 1994; 58: 825-9.

15. Miyake H, Hara I, Kamidono S, Eto H. Oxidative DNA damage in patients with prostate cancer and its response to treatment. J Urol 2004; 171: 1533-6.

16. Nagashima M, Tsuda H, Takenoshita S, et al. 8-hydroxydeoxyguanosine levels in DNA of human breast cancer are not significantly different from those of non-cancerous breast tissues by the HPLC-ECD method. Cancer Lett 1995; 90: 157-62.

17. Jaloszynski P, Jaruga P, Olinski R, et al. Oxidative DNA base modifications and polycyclic aromatic hydrocarbon DNA adducts in squamous cell carcinoma of larynx. Free Radic Res 2003; 37: 231-40. 
18. Karihtala P, Kauppila S, Puistola U, Jukkola-Vuorinen A. Divergent behaviour of oxidative stress markers 8-hydroxydeoxyguanosine (8-OHdG) and 4-hydroxy-2-nonenal (HNE) in breast carcinogenesis. Histopathology 2011; 58: 854-62.

19. Toyokuni S, Tanaka T, Hattori Y, et al. Quantitative immunohistochemical determination of 8-hydroxy-2'-deoxyguanosine by a monoclonal antibody N45.1: its application to ferric nitrilotriacetate-induced renal carcinogenesis model. Lab Invest 1997; 76: 365-74.

20. Lindahl T. Instability and decay of the primary structure of DNA. Nature 1993; 362: 709-15.

21. Soini Y, Haapasaari KM, Vaarala MH, Turpeenniemi-Hujanen T, Kärjä V, Karihtala P. 8-hydroxydeguanosine and nitrotyrosine are prognostic factors in urinary bladder carcinoma. Int J Clin Exp Pathol 2011; 4: 267-75.
22. Takahashi S, Hirose M, Tamano S, et al. Immunohistochemical detection of 8-hydroxy-2'-deoxyguanosine in paraffin-embedded sections of rat liver after carbon tetrachloride treatment. Toxicol Pathol 1998; 26: 247-52.

23. Valavanidis A, Vlachogianni T, Fiotakis K, Loridas S. Pulmonary oxidative stress, inflammation and cancer: respirable particulate matter, fibrous dusts and ozone as major causes of lung carcinogenesis through reactive oxygen species mechanisms. Int J Environ Res Public Health 2013; 10: 3886-907.

24. Vaupel P, Harrison L. Tumor hypoxia: causative factors, compensatory mechanisms, and cellular response. Oncologist 2004; 9 Suppl 5: 4-9.

25. Archer SL, Huang J, Henry T, Peterson D, Weir EK. A redox-based O2 sensor in rat pulmonary vasculature. Circ Res 1993; 73: 1100-12. 